\title{
Purification of recovered phosphoric acid by extracting aluminium with di-2-ethylhexyl phosphoric acid
}

\author{
Sini Reuna ${ }^{1}$ (D) Ari Väisänen ${ }^{1}$
}

Received: 14 February 2021 / Accepted: 30 August 2021 / Published online: 19 September 2021

(c) The Author(s) 2021

\begin{abstract}
The extraction of aluminium from dilute phosphoric acid with di-2-ethylhexyl phosphoric acid (DEHPA) was optimized using response surface methodology. The optimization was based on the experimental three-level central composite facecentred design (CCF) and was conducted on real-life samples. The three variables included were $\mathrm{pH}$, extractant concentration and aqueous to organic phase ratio (AO). Under the optimized conditions ( $\mathrm{pH}$ 2.5, 0.6 M DEHPA and AO ratio 1:2), extraction efficiency of $99 \%$ for aluminium in four extraction stages is achieved. The purified phosphoric acid solution can then be utilized by the fertilizing industry. Stripping tests for organic phase loaded with aluminium were conducted with sulphuric acid. Extremely high stripping efficiency was obtained with $0.9 \mathrm{M}$ sulphuric acid resulting in the recovery rate of $88 \%$ in one stage. After stripping, the aluminium sulphate solution can be reused as a precipitation agent for phosphorus in the wastewater treatment process.
\end{abstract}

Keywords Response surface methodology $\cdot$ Optimization $\cdot$ Sewage sludge $\cdot$ Wastewater $\cdot$ Precipitation agent $\cdot$ Solvent extraction

\section{Introduction}

In 2008, the price of phosphate rock skyrocketed, causing a shortage of $\mathrm{P}$ fertilizer, especially in developing countries (Cordell and Neset 2014; Mew 2016). Since then, the development of phosphorus recovery methods from secondary sources has been exponentially increasing (Scopus 2019). One alluring source is sewage sludge, which can contain phosphorus (P) between 0.6 and 6.7 wt.\% (Milieu Ltd et al. 2008). The even higher concentration is found in sewage sludge ash (SSA) which can contain P up to $8 \mathrm{wt} . \%$ (Biswas et al. 2009). For that reason, several leaching methods with acid or alkaline have been presented for SSA (Donatello et al. 2010; Franz 2008; Petzet et al. 2012). However, for instance, in the Nordic countries, less than $5 \%$ of sewage sludge was incinerated in 2016 (EUROSTAT 2019). Thus, it is important to research methods to recover P straight from sewage sludge. Hence, in this study, we present the results,

Sini Reuna

sini.s.reuna@jyu.fi

1 Department of Chemistry, Chemistry of Living Environment, Renewable Natural Resources, University of Jyväskylä, P.O. Box 35, 40014 Jyväskylä, Finland which assisted the Helsinki Region Environmental Services Authority to patent and develop a process called RAVITA ${ }^{\mathrm{TM}}$ (Fred et al. 2019, 2018).

The RAVITA ${ }^{\mathrm{TM}}$ is a process designed to recover phosphorus and nitrogen from municipal wastewater (Rossi et al. 2018). The first step is phosphorus post-precipitation as phosphate salt with aluminium or iron at the end of the wastewater treatment process. This ensures a purer fraction, which contains fewer heavy metals than the sludge formed in conventional chemical precipitation (Eklund et al. 1991). The post-precipitated sludge is then leached with dilute phosphoric acid $\left(\mathrm{H}_{3} \mathrm{PO}_{4}\right)$ and a leaching solution containing aluminium in moderate concentration is obtained (Reuna and Väisänen 2018). Dilute phosphoric acid simplifies the process since there is no need to remove chloride or sulphate ions. This would be the case if hydrochloric acid or sulphuric acid were used as a leaching solution. After leaching, the separation of aluminium with solvent extraction enables it to be recycled to the precipitation step while the purified phosphoric acid with an elevated concentration of $\mathrm{P}$ is a valuable product. A simplified process schematic for phosphorus recovery with RAVITA ${ }^{\text {TM }}$ is presented in Fig. 1. A detailed description of how RAVITA ${ }^{\mathrm{TM}}$ can be added to the conventional 


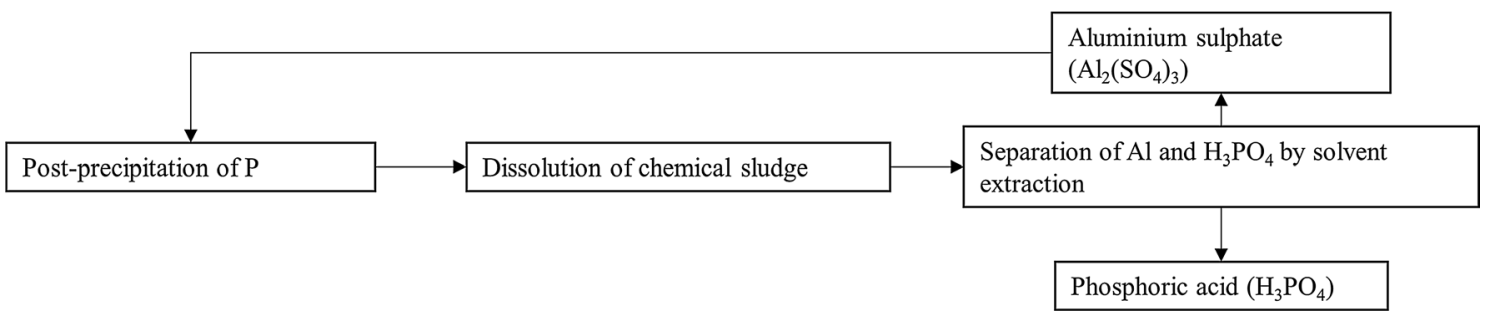

Fig. 1 Process schematic for RAVITA ${ }^{\mathrm{TM}}$

wastewater treatment process to recover both nitrogen and phosphorus is presented in Rossi et al. 2018.

The recovery of aluminium can be performed with di-2-ethylhexyl phosphoric acid (DEHPA). DEHPA is a commercially available acidic organophosphorus extractant that is widely used for uranium recovery from wet processed phosphoric acid and rare earth elements recovery from aqueous solutions (Awwad et al. 2014; Wang et al. 2013; Xie et al. 2014). Mohapatra et al. (Mohapatra et al. 2007) have also used it for the recovery of aluminium from sulphate solutions. In kerosene, DEHPA exists as a dimer and its cation exchange reaction with aluminium can be generally expressed as follows (Mellah and Benachour 2006):

$\mathrm{Al}^{3+}+\overline{n\left[\mathrm{H}_{2} \mathrm{~A}_{2}\right]} \stackrel{\mathrm{K}_{e x}}{\leftrightarrow} \overline{\mathrm{AlH}_{2 n-q} \mathrm{~A}_{2 n}}+q \mathrm{H}^{+}$,

where $K_{\mathrm{ex}}$ is the reaction equilibrium coefficient and $\left[\mathrm{H}_{2} \mathrm{~A}_{2}\right]$ denotes the dimeric form of the extractant. Overbar denotes species present in the organic phase.

This study aims to investigate the effects of $\mathrm{pH}$, aqueous and organic ratio (AO) and concentration of DEHPA to achieve the optimum conditions for aluminium extraction from dilute phosphoric acid solution that is produced from leaching of post-precipitated sewage sludge. The sludge is produced in RAVITA ${ }^{\text {TM}}$-pilot plant located in the Viikinmäki wastewater treatment plant in Helsinki. For the analysis of optimum conditions, the response surface methodology was utilized. The stripping of aluminium from the organic phase is carried out with sulphuric acid, and the parameters AO ratio and concentration of stripping acid are inspected. Sulphuric acid was chosen as the stripping solution because stripping then yields an aluminium sulphate solution, which can be used directly for phosphorus precipitation in the wastewater treatment process. The ability to recirculate aluminium back to precipitation makes the overall process more cost-efficient at a larger scale. The study of recovering and reusing the precipitation reagents in a process is a step towards circular economy and slowly becoming a more common part of process development (Abdel-Ghafar et al. 2019). The obtained results in this work are used as preliminary data for bench-scale and pilot-scale testing of the solvent extraction process.

\section{Experimental}

\section{Materials and chemicals}

All the chemicals used were of analytical grade and used as obtained without further purification. The DEHPA $(97 \%)$ extractant was provided from Sigma-Aldrich. The kerosene, which was used as a diluent, was purchased from Honeywell, Riedel-de Haën. The standard stock solutions of elements (1000 $\mathrm{mg} \mathrm{L}^{-1}$ ) were supplied by PerkinElmer. Phosphoric acid (85 wt.\%), ammonia (40 wt.\%) and $\mathrm{NaCl}(99.99 \%)$ were obtained from VWR International. Nitric acid (65-68 wt.\%), hydrochloric acid (37-39 wt.\%) and sulphuric acid (37-39 wt.\%) were purchased from Sigma-Aldrich. High-purity water produced by the Elga Purelab Ultra water purification system (Buckinghamshire, U.K.) was used throughout the experiments.

\section{Experimental design}

Central composite face-centred design with three independent variables: $\mathrm{pH}(\mathrm{pH})$, the concentration of the extractant ([DEHPA]) and the aqueous to the organic ratio (AO) at three levels $( \pm 1,0)$, including six replicate at the centre point, was used to design the experiments. The variables and their values are shown in Table 1. The experimental runs were randomized to reduce bias from extraneous or uncontrollable conditions. The design was generated with Minitab 18 software. The response variable $(Y)$ was the extraction efficiency $(E \%)$ of aluminium into the organic phase, which is calculated as follows:

$E \%=\frac{\left[\mathrm{C}_{\mathrm{o}}\right]-\left[\mathrm{C}_{\mathrm{e}}\right]}{\left[\mathrm{C}_{\mathrm{o}}\right]} \cdot 100 \%$,

where $C_{o}$ is the initial concentration of aluminium and $C_{e}$ is the aluminium concentration in the aqueous phase after 
Table 1 Coded and actual levels of variables in the experimental design

\begin{tabular}{lllll}
\hline \multirow{2}{*}{ Factors } & Coded term & Levels & & \\
\cline { 5 - 5 } & Lowest -1 & Centre 0 & Highest +1 \\
\hline $\mathrm{pH}$ & $\mathrm{pH}$ & 1.7 & 2.1 & 2.5 \\
Concentration of extractant/M & {$[$ DEHPA] } & 0.3 & 0.45 & 0.6 \\
Aqueous to organic ratio & $\mathrm{AO}$ & $1: 2$ & $1: 1$ & $2: 1$ \\
\hline
\end{tabular}

extraction. The experimental design and individual results are presented in supplementary data (Table S1).

\section{Statistical analysis}

The response surface analysis of the Minitab 18 software was used to analyse the experimental data and to produce the response surface plot. The experimental data were fitted to a second-order polynomial model and regression coefficients were obtained. The generalized second-order response surface model used in the response surface analysis was as follows:

$Y=\beta_{0}+\sum_{i=1}^{k} \beta_{i} x_{i}+\sum_{i=1}^{k} \beta_{i i} x_{i}^{2}+\sum \sum_{i<j}^{k} \beta_{i j} x_{i} x_{j}+\epsilon$,

where $Y$ is the response (aluminium extraction efficiency), $\beta_{0}$ is a constant coefficient, $\beta_{i}$ is the linear effect, $\beta_{i i}$ is the quadratic effect, $\beta_{i j}$ is the interaction effect and $\epsilon$ is the error observed in response (Montgomery 2009).

\section{The procedure of extraction and stripping}

The extraction experiments were carried out in separating funnels by using Stuart SF1 -flask shaker (600 osc/min). The organic and aqueous phases were allowed to separate, and samples were prepared from the aqueous phase. Aluminium concentrations in organic phases were calculated based on mass balance. The experiments were conducted at temperatures of $21-23{ }^{\circ} \mathrm{C}$. The phase contact time of 10 min was used and the volume ratios of organic and aqueous phases varied between 4:1 and 1:4. The $\mathrm{pH}$ was adjusted with $5 \mathrm{M}$ ammonia. Stripping was performed in a water bath at $50{ }^{\circ} \mathrm{C}$. Phases were stirred with a blade mixer and a contact time of 30 min was applied. The organic and aqueous phases were allowed to separate, and samples were prepared from the aqueous phase. The volume ratios of aqueous and organic phases between 1:1 and 1:6 were tested. Any changes to these parameters are reported in the text.

The aqueous phase was produced according to the optimum leaching conditions for moist post-precipitated sludge presented in Reuna and Väisänen (2018). This resulted in an aqueous phase, which contained aluminium in a range of 2.0-2.5 $\mathrm{g} \mathrm{L}^{-1}$ in $0.5 \mathrm{M}$ phosphoric acid and had an initial $\mathrm{pH}$ of 1.7. The variation of aluminium concentration is due to a fact that we used actual post-precipitated sewage sludge (PPS) to produce the leachate. For stripping experiments, the loaded organic phase was prepared by extracting the aqueous phase ( $\mathrm{pH}$ 2.5) with 0.6 M DEHPA diluted in kerosene with $\mathrm{AO}$ ratio of $1: 1$.

\section{The ICP-OES measurements}

The aluminium concentrations in aqueous phases were determined with a PerkinElmer inductively coupled plasmaoptical emission spectrometer (ICP-OES) Optima 8300. The GemCone low flow nebulizer with a cyclonic spray chamber was used for sample introduction. The measurement parameters for all measurements were as follows: argon gas flow of $8 \mathrm{~L} \mathrm{~min}^{-1}$, nebulizer gas flow of $0.6 \mathrm{~L} \mathrm{~min}^{-1}$, auxiliary gas flow of $0.2 \mathrm{~L} \mathrm{~min}^{-1}$, sample flow rate of $1.5 \mathrm{~L} \mathrm{~min}^{-1}$ and the radio frequency power of $1500 \mathrm{~W}$. The measured wavelength in radial view was $396.153 \mathrm{~nm}$ and the calibration range was 5-50 mg L ${ }^{-1}$. The method detection limit for aluminium was determined according to the U.S. Environmental Protection Agency method 200.7 (U. S. Environmental Protection Agency 2001) and it was calculated to be $30 \mu \mathrm{g} \mathrm{L}^{-1}$.

\section{Results and discussion}

\section{Extraction}

\section{Analysis of variance and fitting of the second-order model}

The second-order model was first fitted according to Eq. (3). To achieve an improved model, insignificant model terms were removed by the backward elimination technique. The resulting analysis of variance (ANOVA) data for the reduced quadratic model of extraction is presented in Table 2. The calculated $F$-value for this model was 20.22 and the corresponding $P$-value is less than 0.0001 . Thus the model is significant and can be used for optimization. All first-order terms are significant meaning that all three parameters affect the extraction. The $P$-value for the lack-of-fit is 0.373 , which indicates that it is not significant. The goodness-of-fit of the model can be checked from the coefficient of determination $\left(R^{2}\right)$. The $R^{2}$-value is high, $90.32 \%$, which means that only $9.68 \%$ of the total sample variation cannot be explained by the model. The adjusted $R^{2}$-value of $85.85 \%$ indicates 
Table 2 Analysis of variance table for aluminium extraction with DEHPA

\begin{tabular}{lllllll}
\hline Source & DF & Adj SS & Adj MS & $F$-value & $P$-value & Remarks \\
\hline Model & 6 & 3789.40 & 631.57 & 20.22 & 0.000 & \\
Linear & 3 & 3587.50 & 1195.83 & 38.28 & 0.000 & Signif \\
pH & 1 & 1241.00 & 1241.00 & 39.73 & 0.000 & \\
[DEHPA] & 1 & 577.60 & 577.60 & 18.49 & 0.001 & \\
AO & 1 & 1768.90 & 1768.90 & 56.63 & 0.000 & \\
Square & 2 & 151.90 & 75.95 & 2.43 & 0.127 & \\
pH*pH & 1 & 102.60 & 102.60 & 3.28 & 0.093 & \\
AO*AO & 1 & 136.76 & 136.76 & 4.38 & 0.057 & \\
2-Way interaction & 1 & 50.00 & 50.00 & 1.60 & 0.228 & \\
[DEHPA]*AO & 1 & 50.00 & 50.00 & 1.60 & 0.228 & \\
Error & 13 & 406.06 & 31.24 & & & \\
Lack-of-fit & 9 & 312.56 & 34.73 & 1.49 & 0.373 & Not signif \\
Pure error & 4 & 93.50 & 23.38 & & & \\
Total & 19 & 4195.46 & & & & \\
Model summary: & $R^{2}(\%)$ & $R_{\text {adj }}^{2}(\%)$ & $R_{\text {pred }}^{2}(\%)$ & & & \\
& 90.32 & 85.85 & 74.32 & & & \\
\hline
\end{tabular}

that all the factors included in the model affect the response variable.

The regression equation for the model in uncoded units was obtained as follows:

$$
\begin{aligned}
\mathrm{Y}= & -207.9+176.5 \cdot \mathrm{pH}+50.7 \cdot[\mathrm{DEHPA}] \\
& -5.80 \cdot \mathrm{AO}-35.4 \cdot \mathrm{pH}^{2} \\
& +6.54 \cdot \mathrm{AO}^{2}-16.7([\mathrm{DEHPA}] \cdot \mathrm{AO})
\end{aligned}
$$

where $Y$ is the extraction efficiency of aluminium (\%), [DEHPA] is extractant concentration (M) and AO is the aqueous to organic ratio. The regression equation can be used to estimate the extraction efficiency of aluminium from the phosphoric acid solution within the factor limits. To verify the model assumptions, the residual plots were analysed in supplementary data (Fig. S1).

\section{Effect of variables on extraction efficiency}

Response surface plots were defined based on Eq. (4), to examine the effects of variables $(\mathrm{pH}$, extractant concentration and $\mathrm{AO}$ ratio) on extraction efficiency (Fig. 2). In each plot, one variable is kept constant at level 0 .

Only extractant concentration vs AO interaction term is present in the reduced quadratic model for aluminium extraction efficiency. However, two quadratic effects, $\mathrm{pH}$ and $\mathrm{AO}$, are present. Figure $2 \mathrm{a}$ shows that the interaction between the extractant concentration and the aqueous to organic ratio forms a plane with a curving slope. No clear maximum can be found in Fig. 2a, but the highest result $(59.6 \%)$ is obtained when the molar ratio of extractant and aluminium is at its highest point. At that point, extractant concentration is at the highest level and volume of the organic phase is at maximum. A more concentrated DEHPA concentration could be used for solvent extraction. However, this would require the use of a modifier in the organic phase to enhance the phase separation. Figures $2 b$-c depict interaction terms that are not included in the model. In both cases, a plane with a bent slope is formed and the highest efficiencies are reached when extractant concentration and $\mathrm{pH}$ are at the highest level and AO ratio is on the lowest level (1:2). The same phenomenon can be seen from the main effect plots, which are presented in supplementary data (Fig. S2).

\section{Optimization and verification of the model}

To find the highest extraction efficiency of aluminium within the factor limits, the predicted value for aluminium extraction was calculated based on Eq. (4) using the highest factor levels for $\mathrm{pH}$ and extractant concentration and the lowest level for the AO ratio. This resulted in the predicted extraction efficiency value of $64.9 \%$ with a $95 \%$ confidence interval of $56.1-73.7 \%$.

The model was verified by performing a test with three replicates where aqueous phase $\left(\mathrm{Al} 2.4 \mathrm{~g} \mathrm{~L}^{-1}\right)$ was contacted with organic phase using the highest factor levels for $\mathrm{pH}(2.5)$ and extractant concentration $(0.6 \mathrm{M})$ and the lowest level for the AO ratio (1:2). The verification test resulted in an extraction efficiency of $69 \pm 5 \%$ for aluminium. The result is slightly higher than what the model predicted, resulting in an error percentage of $+4.1 \%$. It can be concluded that the regression model acquired is realistically accurate for predicting aluminium extraction.

The obtained result from the verification test is also supported by experimental data. Experimentally, the highest obtained extraction efficiency was 64\% (Table S1 in 

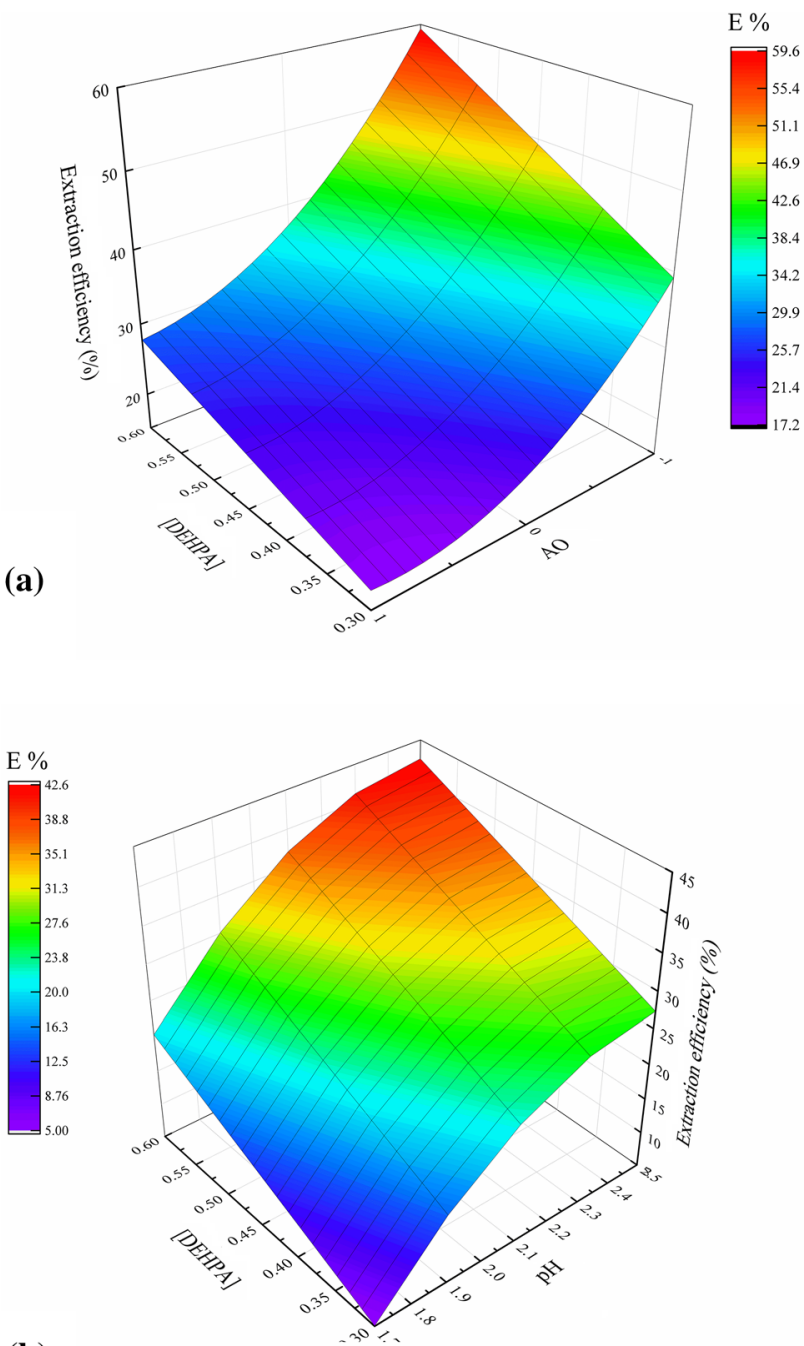

(b)

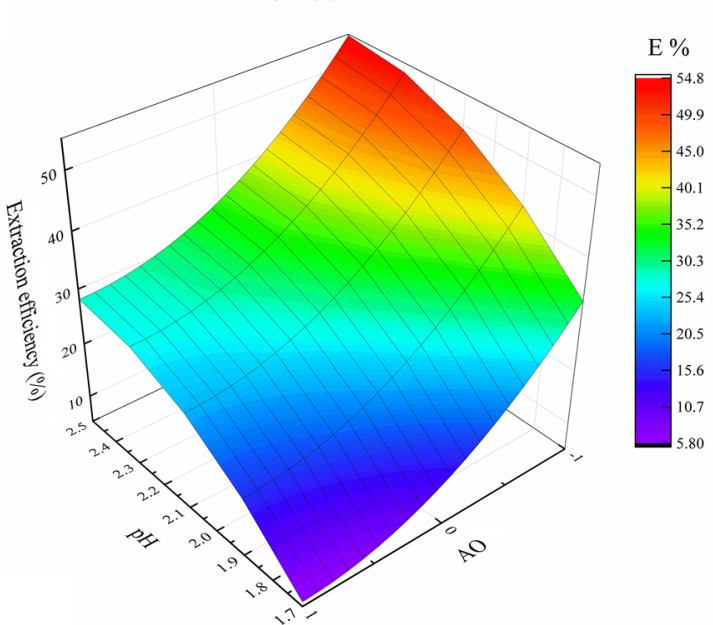

Fig. 2 Changes in extraction efficiency of aluminium concerning a extractant concentration (M) and $\mathrm{AO}$ ratio, $\mathbf{b}$ extractant concentration (M) and $\mathrm{pH}$, and $\mathbf{c} \mathrm{pH}$ and $\mathrm{AO}$ ratio supplementary data) and it was achieved when $\mathrm{pH}$ and extractant concentration are at the highest level, 2.5 and $0.6 \mathrm{M}$, respectively, and the AO ratio is at the lowest level (1:2). The extractant concentration of $0.6 \mathrm{M}$ is higher than that of Mohapatra et al. (2007) discovered as they investigated aluminium recovery with DEHPA from mixed sulphate solutions. Their results indicated that only $0.3 \mathrm{M}$ of Na-DEHPA was sufficient to extract aluminium. However, they only had nickel and cobalt as competing elements while the phosphoric acid solution contains several metallic impurities $(\mathrm{Fe}, \mathrm{Ca}$, and $\mathrm{Mg}$ ) that compete with aluminium in the cation exchange reaction (Reuna and Väisänen 2020). Also, Mohapatra et al. (2007) had a higher equilibrium $\mathrm{pH}$. Nevertheless, the $\mathrm{pH}$ cannot be increased with the phosphoric acid solution because the aluminium phosphate precipitates at a pH above 2.5 (Levlin and Hultman 2004).

\section{Distribution ratio and extraction equilibrium}

The distribution ratio $(D)$ is defined as the ratio of metal concentration in the organic phase to the aqueous phase at equilibrium (Harris 2010). It is expressed as follows:

$D=\frac{\left[C_{\text {org }}\right]_{\text {total }}}{\left[C_{\text {aq }}\right]_{\text {total }}}$,

where $C_{\mathrm{aq}}$ and $C_{\text {org }}$ are the total concentrations of the element in the aqueous and organic phases, respectively. Knowing the cation exchange reaction of DEHPA with aluminium (Eq. 1) the distribution ratio can be expressed as follows:

$D=\frac{\left[\mathrm{AlH}_{2 n-q} \mathrm{~A}_{2 n}\right]_{\mathrm{org}}}{\left[\mathrm{Al}^{q+}\right]_{\mathrm{aq}}}$

then the reaction equilibrium coefficient is as follows:

$K_{\mathrm{ex}}=\frac{\mathrm{D} \cdot\left[\mathrm{H}^{+}\right]^{q}}{\left[\left[\mathrm{H}_{2} \mathrm{~A}_{2}\right]\right]^{n}}$

Taking the logarithm of Eq. (7) and rearranging, the equation can be reduced to (Mohapatra et al. 2007; Sarangi et al. 1999):

$\log K_{\mathrm{ex}}=\log D+q \log \left[\mathrm{H}^{+}\right]-n \log \left[\left[\mathrm{H}_{2} \mathrm{~A}_{2}\right]\right]$

$\log D=\log K_{\mathrm{ex}}-q \log \left[\mathrm{H}^{+}\right]+n \log \left[\left[\mathrm{H}_{2} \mathrm{~A}_{2}\right]\right]$

By plotting the log-log graph of the distribution ratio as a function of equilibrium $\mathrm{pH}$ or the concentration of extractant, it is possible to determine the number of released protons to one aluminium ion $(q)$ or the number of extractant molecules complexed with aluminium ( $n$ ) from the slope of the graph. 
However, this requires that the other parameters and ionic strength are constant.

To determine the number of released protons $(q)$, the aqueous phase $\left(2.4 \mathrm{~g} \mathrm{~L}^{-1} \mathrm{Al} 0.5 \mathrm{M} \mathrm{H}_{3} \mathrm{PO}_{4}\right)$ with adjusted $\mathrm{pH}$ was extracted with 0.6 M DEHPA in kerosene in AO ratio 1:1. To maintain constant ionic strength, 1 molar concentration of $\mathrm{NaCl}$ was added to the aqueous phase. Figure 3 shows the $\log -\log$ graph of the distribution ratio as a function of equilibrium $\mathrm{pH}$. The slope of $2.95 \pm 0.3$ is indicating that three protons are released during extraction. Pearson's correlation coefficient for the linear fitting resulted in 0.984, which shows adequate fitting.

The number of extractant molecules complexed with aluminium ( $n$ ) was determined by Mahimo et al. (Mashimo et al. 1997). When investigating the aluminium equilibrium reaction with DEHPA in sulphuric acid media, they deduced that two molecules of dimeric DEHPA are needed for the reaction. Wu et al. (Wu et al. 2018) came to the same conclusion with rare earth elements, which typically occur as trivalent cations like aluminium. Using the information above, the cation exchange reaction can be written:

$\mathrm{Al}^{3+}+\overline{2\left[\mathrm{H}_{2} \mathrm{~A}_{2}\right]} \stackrel{\mathrm{K}_{e x}}{\leftrightarrow} \overline{\mathrm{AlHA}_{4}}+3 \mathrm{H}^{+}$,

\section{McCabe and Thiele graph for extraction}

The extraction stages required for the full recovery of aluminium from phosphoric acid were determined by contacting the aqueous phase $\left(2.0 \mathrm{~g} \mathrm{~L}^{-1} \mathrm{Al}, \mathrm{pH} 2.5\right)$ with $0.6 \mathrm{M}$ DEHPA at different phase ratios from 0.25 to 4 . Figure 4

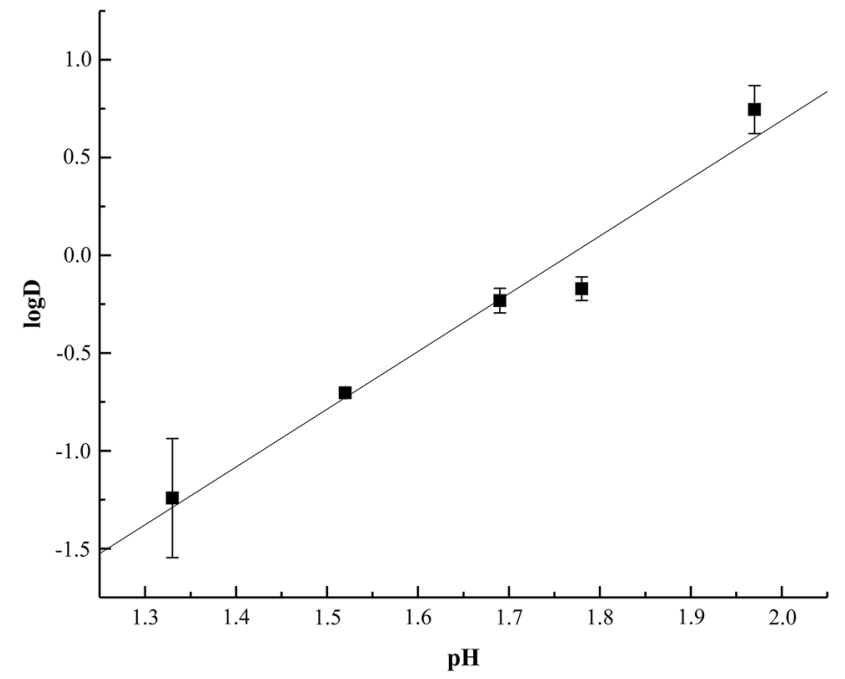

Fig. 3 Effect of $\mathrm{pH}$ on the distribution coefficient of aluminium. Aqueous phase: $\mathrm{Al} 2.4 \mathrm{~g} \mathrm{~L}^{-1} 0.5 \mathrm{M} \mathrm{H}_{3} \mathrm{PO}_{4}$, $\mathrm{AO}$ ratio of $1: 1$, contact time 30 min (Data points: mean \pm standard error of the mean (SEM), $n=3$ ) depicts the obtained extraction isotherms, where each data point is the mean of three replicate tests for each phase ratio. A satisfactory $R^{2}$-value of $97.6 \%$ was attained for polynomial fitting. With the AO ratio of $1: 2$, three theoretical stages are required for the quantitative extraction of aluminium(III). Typically one additional stage is required for complete extraction (Rydberg et al. 2004). This was verified by batch extraction in which the aqueous phase $(2.2 \pm 0.1 \mathrm{~g}$ $\left.\mathrm{L}^{-1} \mathrm{Al}, \mathrm{pH} 2.5\right)$ was extracted four times with the fresh organic phase. The test resulted in the extraction efficiency of $99.0 \pm 0.3 \%$ for aluminium confirming the need for four steps.

\section{Crud formation}

During some of the tests, a formation of crud was observed. This is a common problem in solvent extraction and several factors can be attributed to crud formation (Ritcey, 1980). For instance, with DEHPA the saturation loading should not be exceeded. Since aluminium is one of the main components causing crud formation, the current concentration of aluminium may be too high. However, crud formation can be avoided by changing the AO ratio of extraction. This was proved in McCabe and Thiele's extraction test where no crud was observed with an AO ratio of 1:4. Another prevention method is also a pre-treatment of the aqueous phase with kerosene (Smith et al. 1980). This way crud forming agents are transported into kerosene which can be regenerated with sodium hydroxide. Further, remedies for reducing the crud formation are investigated in forthcoming research.

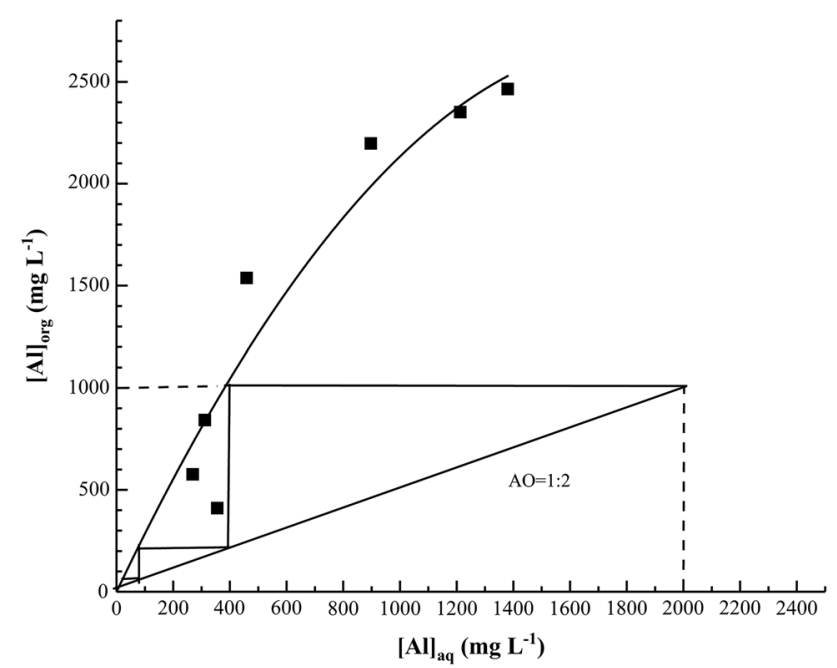

Fig. 4 McCabe-Thiele plot for $\mathrm{Al}(\mathrm{III})$ extraction. Organic phase: $0.6 \mathrm{M}$ DEHPA in kerosene. Aqueous phase: $\mathrm{Al} 2.0 \pm 0.1 \mathrm{~g} \mathrm{~L}^{-1} 0.5 \mathrm{M}$ $\mathrm{H}_{3} \mathrm{PO}_{4}(n=3)$ 


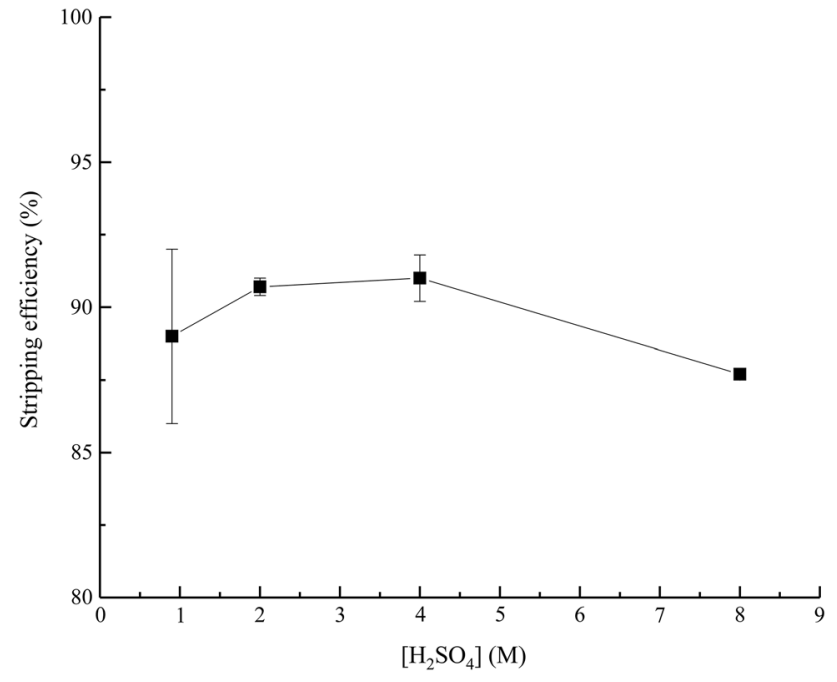

Fig. 5 Effect of stripping acid concentration on the stripping percentage of aluminium (mean $\pm \mathrm{SEM}, n=3$ ). Organic phase: $0.6 \mathrm{M}$ DEHPA in kerosene Al $1.1 \pm 0.1 \mathrm{~g} \mathrm{~L}^{-1}, \mathrm{t}=30 \mathrm{~min}$, AO ratio $1: 1$

\section{Stripping of aluminium from loaded DEHPA}

The aluminium loaded DEHPA was stripped with sulphuric acid in varying concentrations $(0.9-8 \mathrm{M})$. Figure 5 presents the stripping percentage of aluminium from the organic phase with different sulphuric acid concentrations. Table 3 presents the single factor analysis of variance for stripping efficiency of aluminium. ANOVA does not reveal a statistically significant difference between sulphuric acid concentrations since the critical $F$-value (4.066) is higher than the calculated F-value of 1.786. Besides, the acidity of stripping solution containing aluminium should not be unnecessarily elevated. Otherwise, the $\mathrm{pH}$ of the solution should be adjusted before the aluminium is recycled to the precipitation process. For those reasons, $0.9 \mathrm{M}$ concentration was chosen for further testing.

\section{McCabe and Thiele graph for stripping}

The required stripping stages for the complete recovery of aluminium from the organic phase were determined by contacting the aqueous phase with loaded DEHPA at various AO phase ratios from 1:1 to 1:6. Figure 6 depicts the obtained extraction isotherms. An acceptable $R^{2}$-value of $82.4 \%$ was attained for polynomial fitting. With an $\mathrm{AO}$ ratio of $1: 2$, two stages are required for quantitative stripping of $\mathrm{Al}(\mathrm{III})$ with $0.9 \mathrm{M}$ sulphuric acid. In the studies of Mohapatra et al. (2007), only one stage was required for aluminium stripping from the organic phase (0.3 M Na-DEHPA, Al $2.4 \mathrm{~g} \mathrm{~L}^{-1}$ ) because they used slightly higher acid concentration $(1 \mathrm{M})$ and AO ratio 1:1.

Figure 7 illustrates the extraction efficiency of aluminium and the final concentration of $\mathrm{Al}$ at each $\mathrm{AO}$ ratio. As can be seen from Fig. 7, the stripping efficiency starts to diminish after $\mathrm{AO}$ ratio of 1:2 while the aluminium concentration increases throughout the experiment. The decline in efficiency is explained by the decrease of acid versus metal molar ratio. At lower AO ratios, more aluminium is available than sulphuric acid is capable to strip. With a lower AO ratio, it is possible to concentrate $\mathrm{Al}$ in stripping solution, but this would drastically lower the efficiency of one step.

In this study, by using the $\mathrm{AO}$ ratio of 1:2, the aluminium is concentrated by a factor of 1.85 resulting in the aluminium concentration of $2.04 \pm 0.04 \mathrm{~g} \mathrm{~L}^{-1}$. This is accomplished without sacrificing high stripping efficiency. The $\mathrm{P}$ concentration of stripping solution was determined to be $0.25 \pm 0.05 \mathrm{~g} \mathrm{~L}^{-1}$ after one stripping stage at AO 1:2. This indicates that less than $1.5 \%$ of $\mathrm{P}$ is co-extracted with aluminium in the extraction process.

\section{Conclusions}

The extraction of aluminium from dilute phosphoric acid was investigated using di-2-ethylhexyl phosphoric acid (DEHPA) in kerosene. The response surface method
Table 3 Analysis of variance table for stripping of aluminium from loaded DEHPA with sulphuric acid in different concentrations

\begin{tabular}{lllllll}
\hline SUMMARY & \multicolumn{6}{l}{} \\
\hline Groups & Count & Sum & Average & Variance & \\
\hline $0.9 \mathrm{M}$ & 3 & 3052.47 & 1017.49 & 1986.853 & \\
$2 \mathrm{M}$ & 3 & 3123.195 & 1041.065 & 17.11923 & \\
$4 \mathrm{M}$ & 3 & 3132.849 & 1044.283 & 245.8064 & \\
$8 \mathrm{M}$ & 3 & 3019.318 & 1006.439 & 10.85741 & & \\
\hline ANOVA & & & & & & \\
\hline Source of variation & SS & & $d f$ & MS & & \\
\hline Between Groups & 3027.935 & 3 & 1009.312 & 1.78589 & 0.22757 & 4.06618 \\
Within Groups & 4521.271 & 8 & 565.1589 & & & \\
Total & 7549.207 & 11 & & & & \\
\hline
\end{tabular}




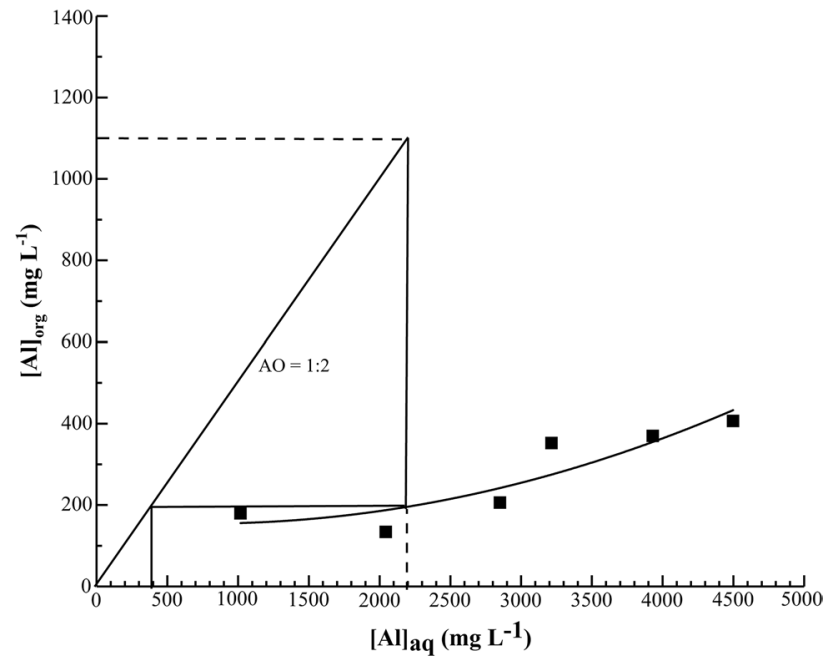

Fig. 6 McCabe-Thiele plot for $\mathrm{Al}^{3+}$ stripping. Organic phase: $0.6 \mathrm{M}$ DEHPA in kerosene $\mathrm{Al} 1.1 \pm 0.1 \mathrm{~g} \mathrm{~L}^{-1}$ Aqueous phase: $0.9 \mathrm{M}$ $\mathrm{H}_{2} \mathrm{SO}_{4}, \mathrm{t}=30 \min (n=3)$

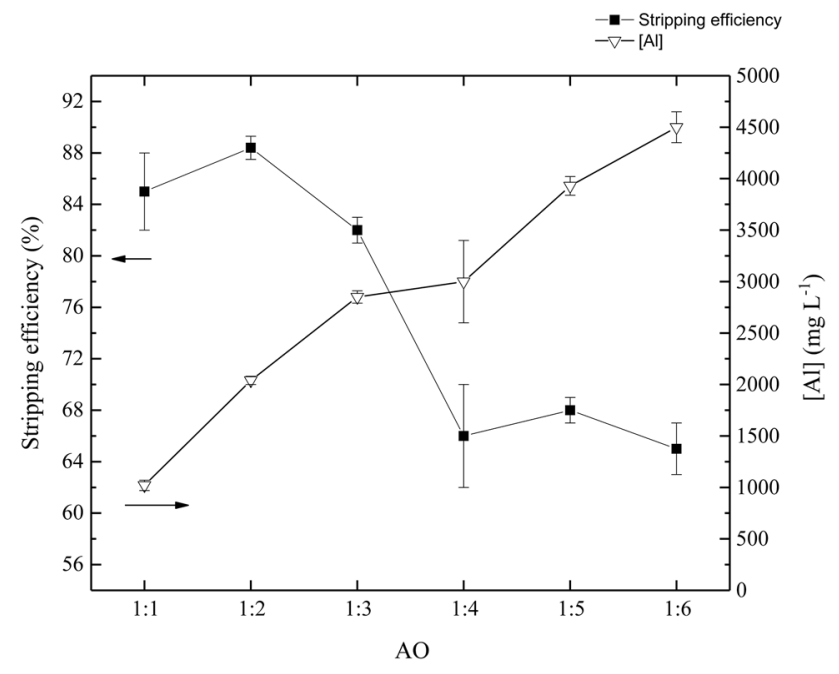

Fig. 7 Stripping efficiencies of aluminium and concentration of $\mathrm{Al}$ in stripping solution. Organic phase: 0.6 M DEHPA in kerosene $\mathrm{Al}$ $1.1 \pm 0.1 \mathrm{~g} \mathrm{~L}^{-1}$ Aqueous phase: $0.9 \mathrm{M} \mathrm{H}_{2} \mathrm{SO}_{4}$, contact time $30 \mathrm{~min}$ $($ mean \pm SEM, $n=3$ )

was used to determine the optimal conditions for solvent extraction at the selected factor levels. To achieve the highest extraction efficiency, the $\mathrm{pH}$ of the aqueous phase and the extractant concentration must be at the highest level, 2.5 and $0.6 \mathrm{M}$, respectively. The aqueous to organic phase ratio must be at the lowest level (1:2) meaning that the molar ratio of extractant and aluminium is at the highest point. The theoretical stages for extraction were deduced with McCabe and Thiele's graph resulting in four steps required for the quantitative extraction of aluminium. This was verified with a batch test that resulted in extraction efficiency of $99.0 \pm 0.3 \%$. For the stripping, two stages are necessary when using the AO ratio of 1:2 and $0.9 \mathrm{M}$ sulphuric acid for the complete recovery of $\mathrm{Al}$. In one stripping step the efficiency is $88.4 \pm 1.4 \%$.

The determined optimized conditions can now be implemented in the process design of the solvent extraction step and thus contribute to the overall development of the RAVITA ${ }^{\mathrm{TM}}$ process, where phosphorus is recovered from wastewater and the precipitation agent (aluminium) is recycled to the precipitation stage. The recycling of the precipitation agent back to phosphorus precipitation is a ground-breaking feature that has not been presented in any other phosphorus recovery processes.

Supplementary Information The online version contains supplementary material available at https://doi.org/10.1007/s11696-021-01848-9.

Acknowledgements This research has received funding from the RAKI Programme of the Ministry of the Environment of Finland. Also, the financial support of Helsinki Region Environmental Services Authority and Department of Chemistry of the University of Jyväskylä is gratefully acknowledged. The corresponding author would also thank project engineer Laura Rossi who kindly manufactured the original RAVITA $^{\mathrm{TM}}$ sludge.

Authors' contributions SR: Conceptualization, Investigation, Formal analysis, Writing-Original Draft, Writing—Review \& Editing, Visualization. AV: Supervision, Writing—review \& editing.

Funding Open access funding provided by University of Jyväskylä (JYU). This research has received funding from the RAKI Programme of the Ministry of the Environment of Finland. Also, the financial support of Helsinki Region Environmental Services Authority is acknowledged.

Availability of data and material Data will be made available upon request.

Code availability Not applicable.

\section{Declarations}

Conflict of interest We are reporting that both the European Patent Office and U.S Patent Agency have granted a patent (European Patent no. 3222587 and US Patent No.: US 10,351,428 B2) for the funder Helsinki Region Environmental Services Authority based on the results presented in this paper. The corresponding author S.R. has been nominated as one of the inventors.

Open Access This article is licensed under a Creative Commons Attribution 4.0 International License, which permits use, sharing, adaptation, distribution and reproduction in any medium or format, as long as you give appropriate credit to the original author(s) and the source, provide a link to the Creative Commons licence, and indicate if changes were made. The images or other third party material in this article are included in the article's Creative Commons licence, unless indicated otherwise in a credit line to the material. If material is not included in the article's Creative Commons licence and your intended use is not permitted by statutory regulation or exceeds the permitted use, you will 
need to obtain permission directly from the copyright holder. To view a copy of this licence, visit http://creativecommons.org/licenses/by/4.0/.

\section{References}

Abdel-Ghafar HM, Abdel-Aal EA, Ibrahim MAM, El-Shall H, Ismail AK (2019) Purification of high iron wet-process phosphoric acid via oxalate precipitation method. Hydrometallurgy 184:1-8. https://doi.org/10.1016/j.hydromet.2018.12.011

Awwad NS, El-Nadi YA, Hamed MM (2014) Successive processes for purification and extraction of phosphoric acid produced by wet process. Chem Eng Process Process Intensif 74:69-74. https:// doi.org/10.1016/j.cep.2012.11.009

Biswas BK, Inoue K, Harada H, Ohto K, Kawakita H (2009) Leaching of phosphorus from incinerated sewage sludge ash by means of acid extraction followed by adsorption on orange waste gel. J Environ Sci 21:1753-1760. https://doi.org/10.1016/S10010742(08)62484-5

Cordell D, Neset TSS (2014) Phosphorus vulnerability: A qualitative framework for assessing the vulnerability of national and regional food systems to the multi-dimensional stressors of phosphorus scarcity. Glob Environ Chang 24:108-122. https://doi.org/10. 1016/j.gloenvcha.2013.11.005

Donatello S, Tong D, Cheeseman CR (2010) Production of technical grade phosphoric acid from incinerator sewage sludge ash (ISSA). Waste Manag 30:1634-1642. https://doi.org/10.1016/j.wasman. 2010.04.009

Eklund L, Hellstrom BG, Hultman B, Lind JE, Nordstrom B (1991) Swedish full-scale experiments on modified operational modes in removal of nutrients. Water Sci Technol 24:97-102

EUROSTAT, 2019. Sewage sludge production and disposal from urban wastewater (in dry substance (d.s)) [WWW Document]. https:// ec.europa.eu/eurostat/web/products-datasets/-/env_ww_spd. Accessed 22 Jan 2020

Franz M (2008) Phosphate fertilizer from sewage sludge ash (SSA). Waste Manag 28:1809-1818. https://doi.org/10.1016/j.wasman. 2007.08.011

Fred, T., Heinonen, M., Lindell, P., Reuna, S., 2019. Method of phosphorus removal and recovery. US 10,351,428 B2

Fred, T., Heinonen, M., Lindell, P., Reuna, S., 2018. EP3222587 - A Method of phosphorus removal and recovery. 3222587

Harris DC (2010) Quantitative Chemical Analysis, 8th edn. Freeman and Company, New York

Levlin, E., Hultman, B., 2004. Phosphorus recovery from sewage sludge: ideas for further studies to improve leaching. Proc. PolishSwedish a Semin. Integr. Optim. urban Sanit. Syst. 101-110

Mashimo M, Sato H, Ueda M, Komasawa I (1997) Extraction equilibria of aluminum and beryllium from sulfate media by mixture of bis(2-ethylhexyl) phosphoric acid and dinonylnaphthalene sulfonic acid. J Chem Eng Japan. https://doi.org/10.1252/jcej.30.706

Mellah A, Benachour D (2006) The solvent extraction of zinc and cadmium from phosphoric acid solution by di-2-ethyl hexyl phosphoric acid in kerosene diluent. Chem Eng Process Process Intensif 45:684-690. https://doi.org/10.1016/j.cep.2006.02.004

Mew MC (2016) Phosphate rock costs, prices and resources interaction. Sci Total Environ 542:1008-1012. https://doi.org/10.1016/j. scitotenv.2015.08.045

Milieu Ltd, WRc, RPA, 2008. Environmental, economic and social impacts of the use of sewage sludge on land Final Report Part III: Project Interim Reports. Brussels

Mohapatra D, Hong-In K, Nam CW, Park KH (2007) Liquid-liquid extraction of aluminium (III) from mixed sulphate solutions using sodium salts of Cyanex 272 and D2EHPA. Sep Purif Technol $56: 311-318$

Montgomery DC (2009) Design and Analysis of Experiments, 7th edn. John Wiley \& Sons Inc, Hoboken

Petzet S, Peplinski B, Cornel P (2012) On wet chemical phosphorus recovery from sewage sludge ash by acidic or alkaline leaching and an optimized combination of both. Water Res 46:3769-3780. https://doi.org/10.1016/j.watres.2012.03.068

Reuna S, Väisänen A (2020) To incinerate or not? - Effects of incineration on the concentrations of heavy metals and leaching efficiency of post-precipitated sewage sludge $\left(\right.$ RAVITA $\left.^{\mathrm{TM}}\right)$. Waste Manag 118:241-246. https://doi.org/10.1016/j.wasman.2020.08.022

Reuna S, Väisänen A (2018) Optimizing the H3PO4 leaching conditions of post-precipitated sewage sludge using response surface methodology. J Environ Manage 226:70-75. https://doi.org/10. 1016/j.jenvman.2018.08.004

Ritcey GM (1980) Crud in solvent extraction processing - a review of causes and treatment. Hydrometallurgy 5:97-107. https://doi.org/ 10.1016/0304-386X(80)90031-6

Rossi L, Reuna S, Fred T, Heinonen M (2018) RAVITA Technology - new innovation for combined phosphorus and nitrogen recovery. Water Sci Technol 78:2511-2517. https://doi.org/10.2166/ wst.2019.011

Rydberg, J., Cox, M., Musikas, C., Choppin, G.R. (eds.), (2004) Solvent extraction principles and practice, 1 st edn. Marcel Dekker Inc

Sarangi K, Reddy BR, Das RP (1999) Extraction studies of cobalt (II) and nickel (II) from chloride solutions using Na-Cyanex 272. Separation of $\mathrm{Co}(\mathrm{II}) / \mathrm{Ni}$ (II) by the sodium salts of D2EHPA, PC88A and Cyanex 272 and their mixtures. Hydrometallurgy 52:253-265. https://doi.org/10.1016/S0304-386X(99)00025-0

Scopus, 2019. Phosphorus recovery Documents by year [WWW Document]. URL https://www.scopus.com/term/analyzer.uri?sid= aa171 eb8aad012700900b812fbfee69f\&origin=resultslist \&src $=$ $\mathrm{s} \& \mathrm{~s}=$ TITLE-ABS-KEY\%28phosphorus+recovery\%29\&sort= plf- $\mathrm{f} \& \mathrm{sdt}=\mathrm{b} \& \mathrm{sot}=\mathrm{b} \& \mathrm{sl}=34 \&$ count $=9308 \&$ analyzeResults $=$ Analyze + results \& tx Gid $=80 \mathrm{c} 5 \mathrm{fb} 6 \mathrm{~d} 7404 \mathrm{~d} 280463 \mathrm{e} 7986 \mathrm{a} 40 \mathrm{ef} 7$ b8. Accessed 19 Nov 2019

Smith, J.C., La, G., Eng, I., Proc, C., Ura, D., 1980. Method of treating phosphoric acid to prevent crud formation during solvent extraction

U. S. Environmental Protection Agency, 2001. Method 200.7. Trace elements in water, solids and biosolids by inductively coupled plasma-atomic emission spectrometry, revision 5.0

Wang W, Pranolo Y, Cheng CY (2013) Recovery of scandium from synthetic red mud leach solutions by solvent extraction with D2EHPA. Sep Purif Technol 108:96-102. https://doi.org/10. 1016/j.seppur.2013.02.001

Wu S, Wang L, Zhang P, El-Shall H, Moudgil B, Huang X, Zhao L, Zhang L, Feng Z (2018) Simultaneous recovery of rare earths and uranium from wet process phosphoric acid using solvent extraction with D2EHPA. Hydrometallurgy 175:109-116. https://doi. org/10.1016/j.hydromet.2017.10.025

Xie F, Zhang TA, Dreisinger D, Doyle F (2014) A critical review on solvent extraction of rare earths from aqueous solutions. Miner Eng 56:10-28. https://doi.org/10.1016/J.MINENG.2013.10.021

Publisher's Note Springer Nature remains neutral with regard to jurisdictional claims in published maps and institutional affiliations. 